\title{
THERMAL OVERLOAD RELAY SEBAGAI PENGAMAN OVERLOAD PADA MINIATUR GARDU INDUK BERBASIS PROGRAMMABLE LOGIC CONTROLLER (PLC) CP1E-E40DR-A
}

\author{
Hendy Pradika, Moediyono \\ Program Studi Diploma III Teknik Elektro \\ Fakultas Teknik Universitas Diponegoro
}

\begin{abstract}
Hendy Pradika, Moediyono, in paper thermal overload relay as a overload safety in miniature of substation based on programmable logic controller (PLC) CPIE-E4ODR-A explain that at the substation there is a protective device that is very vital function, which we often refer breaker Power (PMT) or also called Circuit Breaker $(C B)$. The function of the PMT itself is to connect or disconnect current / power corresponding branches if there is interference in substations or other transmission device or in the event of overload. At the substation's miniature PMT function is replaced by a contactor that functions more or less the same. Contactor performance is governed by OMRON CPIE PLC-E4ODR-A which had previously received input from the Thermal Overload Relay in the event of overload. Thermal Overload Relay works on the principle of expansion and bimetal objects. When exposed to high current object, then the object will expand so it will bend and break the current. Excessive current will generate heat, so it can bend bimetal.Hal object will cause the contactor is connected to the Thermal Overload Relay will decide the electric current through the contactor. With this tool, we can realize the expected electric power system more secure in terms of security and reliability so as not to harm humans and the environment.
\end{abstract}

Keywords: substations, protection, PMT, overload, contactors, Thermal Overload Relay, Omron PLC CPIEE40DR-A

\section{PENDAHULUAN \\ Latar Belakang}

Perkembangan teknologi di segala bidang, semua hal dituntut untuk dapat mengikuti perkembangan itu. Kemajuan teknologi biasanya ditandai dengan semakin majunya kontrol otomatis dalam dunia industri sehingga semakin diperlukan efisiensi kontrol otomatis. Untuk itu dibutuhkan suatu kendali yang dapat mengontrol bekerjanya suatu alat atau mesin-mesin secara otomatis. Di sinilah Penggunaan PLC diperlukan karena PLC dirancang untuk dapat bekerja secara otomatis dan lebih efesien dibandingkan kontrol lain. Di samping itu PLC dapat diterapkan dalam berbagai bidang.

Di bidang sistem tenaga listrik, masih jarang yang menggunakan PLC sebagai otak dari sistemnya. Misalnya sistem tenaga listrik di Gardu Induk, belum ada yang menggunakan PLC sebagai sistem kontrolnya. Lebih spesifik lagi di bagian Pemutus Tenaga (PMT), salah satu unsur paling penting pada Gardu Induk, masih belum ada yang menggunakan PLC dalam operasinya sebagai pengaman. Oleh karena itu muncullah ide untuk membuat miniatur gardu induk yang sistem kontrolnya menggunakan PLC.

\section{LANDASAN TEORI \\ Gardu Induk}

Gardu Induk merupakan sub sistem dari sistem penyaluran (transmisi) tenaga listrik, atau merupakan satu kesatuan dari sistem penyaluran (transmisi). Penyaluran (transmisi) merupakan sub sistem dari sistem tenaga listrik. Berarti, gardu induk merupakan sub-sub sistem dari sistem tenaga listrik. Sebagai sub sistem dari sistem penyaluran (transmisi), gardu induk mempunyai peranan penting, dalam pengoperasiannya tidak dapat dipisahkan dari sistem penyaluran (transmisi) secara keseluruhan.

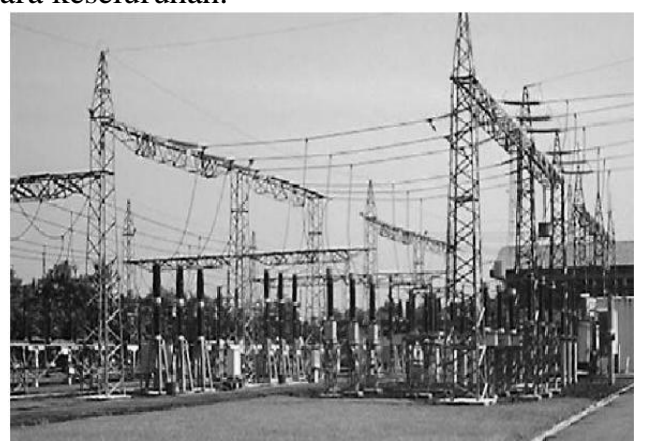

Gambar 1. Gardu Induk Konvensional

\section{Pemutus Tenaga (PMT)}

Circuit breaker $(\mathrm{CB})$ atau Pemutus Tenaga (PMT) adalah peralatan pada sistem tenaga listrik yang berfungsi untuk memutuskan hubungan antara sisi sumber tenaga listrik dan sisi beban, yang dapat bekerja secara otomatis dalam keadaan berbeban ataupun tidak berbeban yang dilengkapi sistem proteksi arus hubung singkat, ketika terjadi gangguan atau secara manual ketika dilakukan perawatan atau perbaikan. 


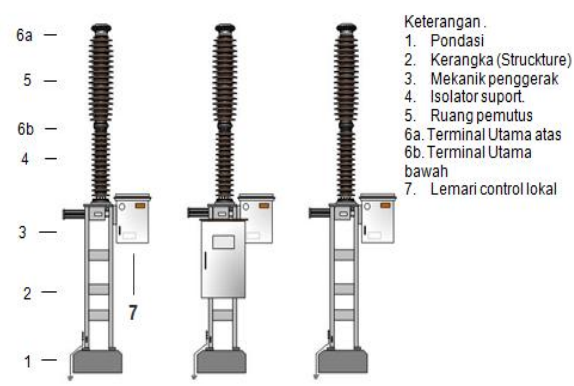

Gambar 2. PMT Single Pole

\section{Proses Terjadinya Busur Api}

Pada waktu pemutusan atau penghubungan suatu rangkaian sistem tenaga listrik maka pada PMT (circuit breaker) akan terjadi busur api, hal tersebut terjadi karena pada saat kontak PMT dipisahkan, beda potensial diantara kontak akan menimbulkan medan elektrik diantara kontak tersebut, seperti ditunjukkan pada gambar dibawah.

Arus yang sebelumnya mengalir pada kontak akan memanaskan kontak dan menghasilkan emisi thermis pada permukaan kontak. Sedangkan medan elektrik menimbulkan emisi medan tinggi pada kontak katoda (K). Kedua emisi ini menghasilkan elektron bebas yang sangat banyak dan bergerak menuju kontak anoda (A). Elektronelektron ini membentur molekul netral media isolasi dikawasan positif, benturan-benturan ini akan menimbulkan proses ionisasi. Dengan demikian, jumlah elektron bebas yang menuju anoda akan semakin bertambah dan muncul ion positif hasil ionisasi yang bergerak menuju katoda, perpindahan elektron bebas ke anoda menimbulkan arus dan memanaskan kontak anoda.

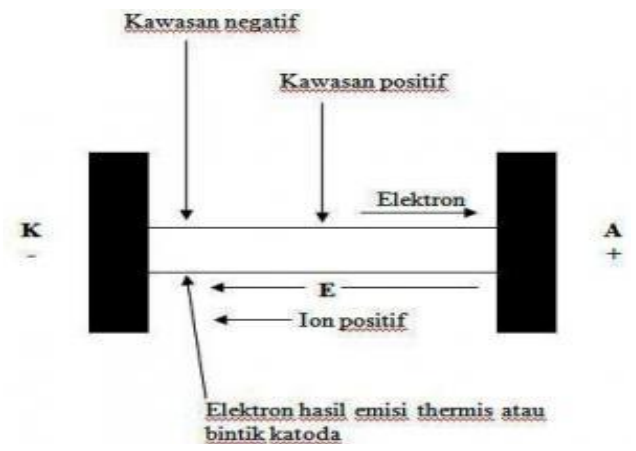

Gambar 3. Perpindahan elektron bebas ke anoda

Ion positif yang tiba di kontak katoda akan menimbulkan dua efek yang berbeda. Jika kontak terbuat dari bahan yang titik leburnya tinggi, misalnya tungsten atau karbon, maka ion positif akan akan menimbulkan pemanasan di katoda. Akibatnya, emisi thermis semakin meningkat. Jika kontak terbuat dari bahan yang titik leburnya rendah, misal tembaga, ion positif akan menimbulkan emisi medan tinggi. Hasil emisi thermis ini dan emisi medan tinggi akan melanggengkan proses ionisasi, sehingga perpindahan muatan antar kontak terus berlangsung dan inilah yang disebut busur api.

\section{PLC}

PLC (Programmable Logic Controller) dapat dibayangkan seperti sebuah personal komputer konvensional (konfigurasi internal pada PLC mirip sekali dengan konfigurasi komputer internal pada personal komputer). Tetapi PLC dirancang untuk pembuatan panel listrik arus kuat.

Di dalam otak $(\mathrm{CPU}=$ Control Processing Unit) PLC dapat dibayangkan seperti kumpulan ribuan relay. Akan tetapi bukan berarti didalamnya terdapat banyak relay dalam ukuran yang sangat kecil. Di dalam PLC berisi rangka elektronika digital yang dapat difungsikan seperti Contact Relay (baik NO maupun NC) pada PLC dapat digunakan berkali-kali untuk semua instruksi dasar selain instruksi output. Jadi dikatakan bahwa dalam suatu program PLC tidak diijinkan menggunakan output dengan nomor kontak yang sama.

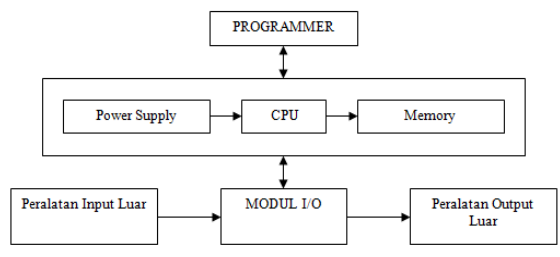

Gambar 4. Diagram Prinsip Kerja PLC

\section{One}

CX One (Programmer) adalah salah satu perangkat lunak yang digunakan untuk menyiapkan sistem pemrograman, memasukkan data program, memonitor operasi sistem dan menjalankan program. CX One (Programmer) digunakan dengan menggunakan perangkat komputer.

Instruksi ladder diagram dapat secara langsung diprogram ke PLC, tidak seperti melalui programming console, yang harus diubah dulu ke dalam bentuk mnemonic. Jadi penggunaan perangkat lunak ini dirasa lebih mudah dan praktis dibanding pemrograman menggunakan programming console.

\section{Relay}

Relay adalah salah satu alat elektromagnet yang sederhana. Relay dapat terdiri dari sebuah kumparan atau solenoid, sebuah inti feromagnetik dan sebuah armatur yang dapat bergerak yang merupakan tempat terpasangnya kontak yang berfungsi sebagai penyambung dan pemutus.

\section{Thermal Overload Relay}

Thermal relay atau overload relay adalah peralatan switching yang peka terhadap suhu dan akan membuka atau menutup kontaktor pada saat suhu yang terjadi melebihi batas yang ditentukan atau peralatan kontrol listrik yang berfungsi untuk 
memutuskan jaringan listrik jika terjadi beban lebih.

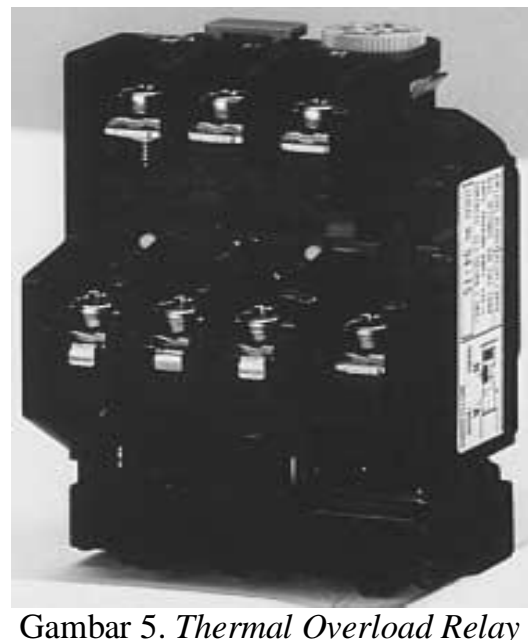

Arus yang terlalu besar yang timbul pada beban motor listrik akan mengalir pada belitan motor listrik yang dapat menyebabkan kerusakan dan terbakarnya belitan motor listrik. Untuk menghindari hal itu dipasang termal beban lebih pada alat pengontrol. Prinsip kerja thermal beban lebih berdasarkan panas (temperatur) yang ditimbulkan oleh arus yang mengalir melalui elemen-elemen pemanas bimetal. Dan sifatnya pelengkungan bimetal akibat panas yang ditimbulkan, bimetal akan menggerakkan kontakkontak mekanis pemutus rangkaian listrik (Kontak 95-96 membuka).

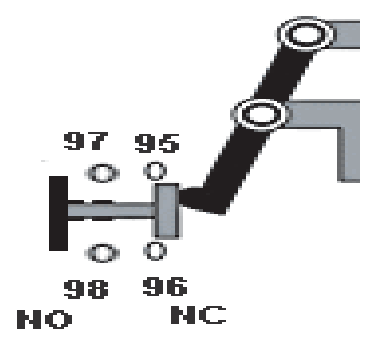

Keadaan normal

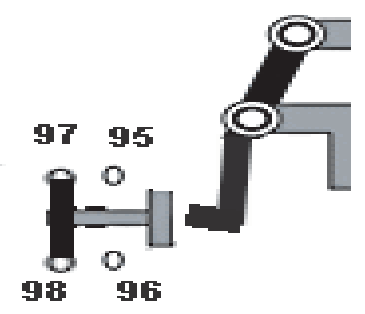

Keadaan trip

Gambar 6. Kondisi kerja Thermal Overload Relay
TOR bekerja berdasarkan prinsip pemuaian dan benda bimetal. Apabila benda terkena arus yang tinggi, maka benda akan memuai sehingga akan melengkung dan memutuskan arus.

Untuk mengatur besarnya arus maksimum yang dapat melewati TOR, dapat diatur dengan memutar penentu arus dengan menggunakan obeng sampai didapat harga yang diinginkan.

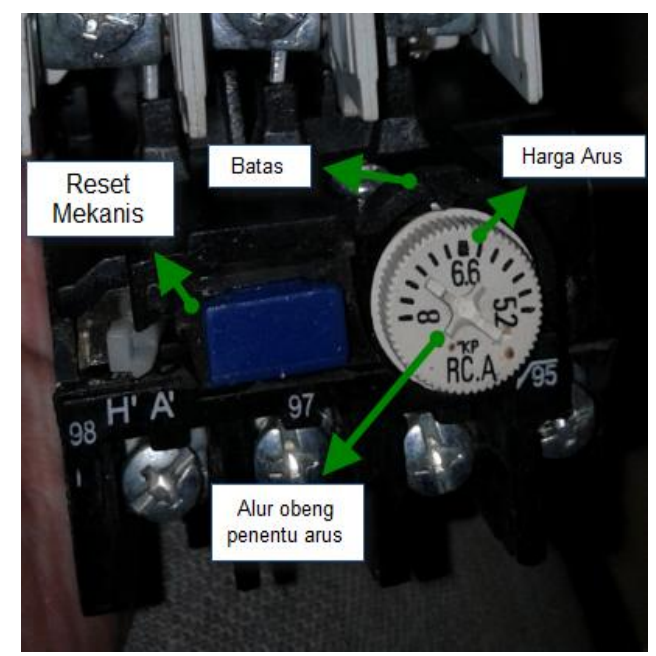

Gambar 7. Pengaturan arus Thermal Overload Relay

\section{Kontaktor}

Kontaktor adalah suatu peralatan listrik arus kuat low voltage sampai dengan tegangan 600 volt AC (Alternating Current) maupun DC (Direct Current) yang mana bisa disebut sebagai saklar pemutus / penghubung arus yang bekerja berdasarkan elektromagnetik. The National Manufacture Assosiation (NEMA) menjelaskan kontaktor magnetis sebagai alat yang digerakan secara magnetis untuk menyambung dan membuka rangkaian daya listrik. Tidak seperti relay, kontaktor dirancang untuk menyambung dan membuka rangkaian daya listrik tanpa merusak.

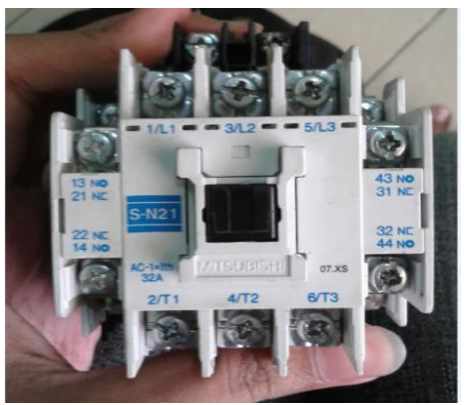

Gambar 8. Kontaktor

\section{Gangguan Overload}

Beberapa penyebab terjadinya beban lebih antara lain:

- Arus start yang terlalu besar atau motor listrik berhenti secara mendadak

- Terjadinya hubung singkat (short circuit) 
- $\quad$ Terbukanya salah satu fasa dari motor listrik 3 fasa.

- Pembebanan yang berlebihan pada jaringan.

\section{PERCOBAAN DAN PENGUKURAN \\ RANGKAIAN}

Terminal I/O PLC

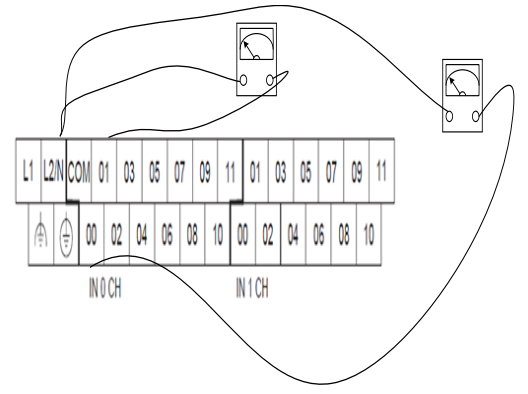

a)

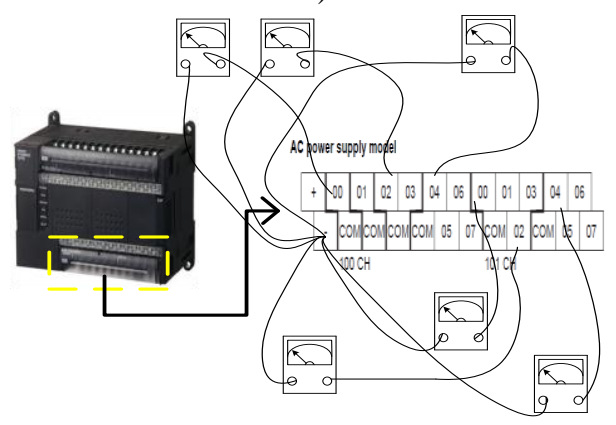

b)

Gambar 9. Titik Pengukuran Terminal PLC a)

Terminal input. b) Terminal output.

Tabel 1a. Hasil Pengukuran Terminal input.

\begin{tabular}{llll}
\hline Alamat & Instruksi & $\begin{array}{l}\text { Saat } \\
\text { mendapat } \\
\text { sinyal }\end{array}$ & $\begin{array}{l}\text { Saat } \\
\text { mendapat } \\
\text { sinyal }\end{array}$ \\
\hline 00000 & $S T A R T$ & $12 \mathrm{~V}$ & $0 \mathrm{~V}$ \\
00001 & $S T A R T 2$ & $12 \mathrm{~V}$ & $0 \mathrm{~V}$ \\
\hline
\end{tabular}

Tabel 1b. Hasil Pengukuran Terminal output.

\begin{tabular}{llll}
\hline Alamat & Instruksi & $\begin{array}{l}\text { Tegangan } \\
\text { sinyal }\end{array}$ & $\begin{array}{l}\text { Tidak } \\
\text { mendapat } \\
\text { sinyal }\end{array}$ \\
\hline 10000 & $\begin{array}{l}\text { PMS Line 2 } \\
\text { Close }\end{array}$ & $13,8 \mathrm{~V} \mathrm{DC}$ & $0 \mathrm{~V}$ \\
10002 & $\begin{array}{l}\text { PMS Bus 2 } \\
\text { Close }\end{array}$ \\
10004 & $\begin{array}{l}\text { PMT 2 Close } \\
10100\end{array}$ & $\begin{array}{l}\text { PMS Line 2 } 2 \\
\text { Open } 13,8 \mathrm{~V} \mathrm{DC}\end{array}$ & $0 \mathrm{~V}$ \\
10102 & $\begin{array}{l}\text { PMS Bus 2 } \\
\text { Open } 13,8 \mathrm{~V} \mathrm{DC}\end{array}$ & $0 \mathrm{~V}$ \\
10104 & PMT 2 Open & $13,5 \mathrm{~V} \mathrm{DC}$ & $0 \mathrm{~V}$ \\
\hline
\end{tabular}

\section{Rangkaian Catu Daya}

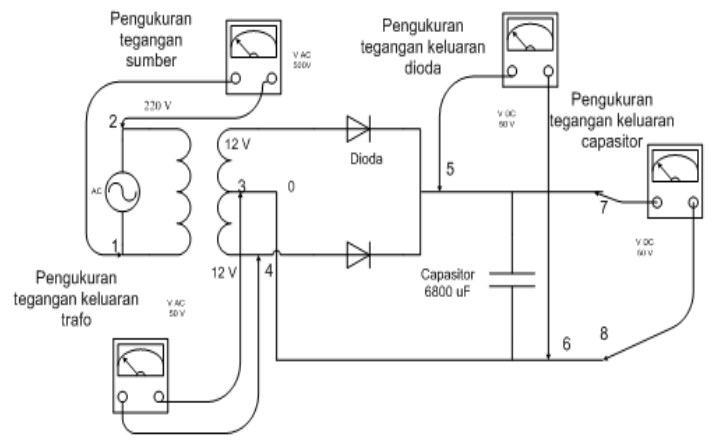

Gambar 10. Pengukuran Catu Daya

Tabel 2. Hasil Pengukuran Catu Daya.

\begin{tabular}{ccccc}
\hline No. & $\begin{array}{c}\text { Kompone } \\
\mathbf{n}\end{array}$ & $\begin{array}{c}\text { Titik } \\
\text { Penguk } \\
\text { uran }\end{array}$ & $\begin{array}{c}\text { Mendapat } \\
\text { sinyal }\end{array}$ & $\begin{array}{c}\text { Tidak } \\
\text { mendap } \\
\text { at sinyal }\end{array}$ \\
\hline 1. & $\begin{array}{c}\text { MCB 1 } \\
\text { phasa }\end{array}$ & $\begin{array}{c}\text { Titik 1- } \\
2\end{array}$ & $220 \mathrm{VAC}$ & $0 \mathrm{~V}$ \\
2. & $\begin{array}{c}\text { Transforma } \\
\text { tor 3A }\end{array}$ & $\begin{array}{c}\text { Titik 3- } \\
4\end{array}$ & $12,5 \mathrm{VAC}$ & $0 \mathrm{~V}$ \\
3. & $\begin{array}{c}\text { Dioda } \\
\text { gelomban } \\
\text { g penuh) }\end{array}$ & $\begin{array}{c}\text { Titik 5- } \\
6\end{array}$ & $16,5 \mathrm{VDC}$ & $0 \mathrm{~V}$ \\
4. & $\begin{array}{c}\text { Kapasitor } \\
\text { (elco) }\end{array}$ & $\begin{array}{c}\text { Titik 7- } \\
8\end{array}$ & $16,8 \mathrm{VDC}$ & $0 \mathrm{~V}$ \\
\hline
\end{tabular}

\section{Pengujian Thermal Overload Relay}

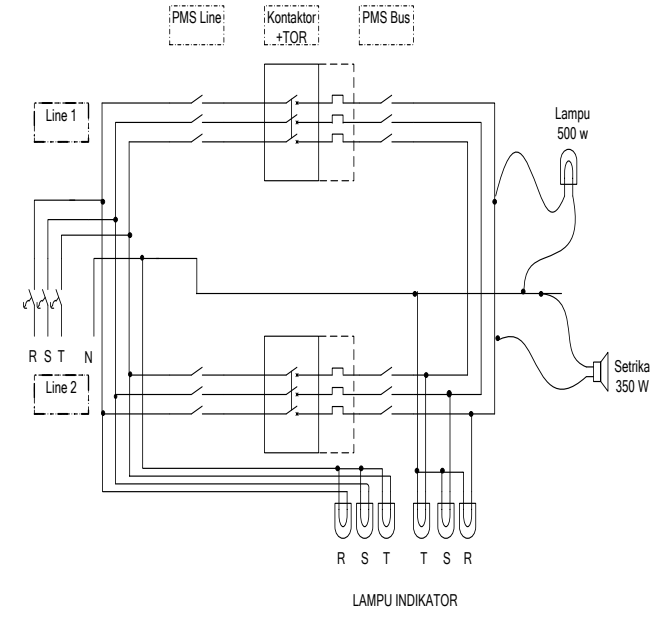

Gambar 11. Titik pemasangan beban pada alat 
Tabel 3. Hasil Uji coba waktu trip Thermal Overload Relay jika diberi beban (Arus max. $\mathrm{TOR}=6 \mathrm{~A})$

\begin{tabular}{|c|c|c|c|c|}
\hline No. & $\begin{array}{l}\text { Jenis } \\
\text { beban }\end{array}$ & $\begin{array}{l}\text { Besar } \\
\text { arus }\end{array}$ & $\begin{array}{l}\text { Pengaruh } \\
\text { terhadap } \\
\text { Kontaktor }\end{array}$ & Waktu \\
\hline 1. & $\begin{array}{l}1 \text { buah } \\
\text { setrika } \\
\text { Philips HI- } \\
114350 \mathrm{~W}\end{array}$ & $1,6 \mathrm{~A}$ & $\begin{array}{l}\text { tidak } \\
\text { terjadi trip }\end{array}$ & - \\
\hline 2. & $\begin{array}{l}1 \text { buah } \\
\text { lampu } \\
\text { Osram } \\
\text { HWL } \\
\text { (MBFT) E- } \\
40500 \mathrm{~W}\end{array}$ & $\begin{array}{l}2,27 \\
\mathrm{~A}\end{array}$ & $\begin{array}{l}\text { tidak } \\
\text { terjadi trip }\end{array}$ & - \\
\hline 3. & $\begin{array}{l}\text { lampu } \\
\text { Osram } \\
\text { HWL } \\
\text { (MBFT) E- } \\
40500 \mathrm{~W} \\
\text { dan setrika } \\
\text { Philips HI- } \\
114350 \mathrm{~W}\end{array}$ & $3,8 \mathrm{~A}$ & $\begin{array}{l}\text { tidak } \\
\text { terjadi trip }\end{array}$ & - \\
\hline 4. & $\begin{array}{l}2 \text { buah } \\
\text { lampu } \\
\text { Osram } \\
\text { HWL } \\
\text { (MBFT) E- } \\
40500 \mathrm{~W}\end{array}$ & $4,5 \mathrm{~A}$ & $\begin{array}{l}\text { tidak } \\
\text { terjadi trip }\end{array}$ & - \\
\hline 5. & $\begin{array}{l}2 \text { buah } \\
\text { lampu } \\
\text { Osram } \\
\text { HWL } \\
\text { (MBFT) E- } \\
40500 \mathrm{~W} \\
\text { dan setrika } \\
\text { Philips HI- } \\
114350 \mathrm{~W}\end{array}$ & $6,1 \mathrm{~A}$ & terjadi trip & $\begin{array}{l}\text { Setelah } \\
8 \text { detik }\end{array}$ \\
\hline 6. & $\begin{array}{l}3 \text { Buah } \\
\text { lampu } \\
\text { Osram } \\
\text { HWL } \\
\text { (MBFT) E- } \\
40500 \mathrm{~W}\end{array}$ & $6,8 \mathrm{~A}$ & terjadi trip & $\begin{array}{l}\text { Setelah } \\
4 \text { detik }\end{array}$ \\
\hline
\end{tabular}

Analisa perhitungan arus yang masuk pada Thermal Overload Relay jika diberi beban supaya TOR bekerja (Arus max. TOR=6 A):

- Beban arus pada 1 setrika 350W: $350 / 220=1,6$ Ampere, tidak terjadi trip.

- Beban arus pada 1 lampu 500W: 500/220= 2,27 Ampere, tidak terjadi trip.

- Beban arus pada 1 lampu 500W dan 1 setrika 350W: 850/220=3,8 Ampere, tidak terjadi trip.

- Beban arus pada 2 lampu 500W: 1000/220= 4,5 Ampere, tidak terjadi trip.

- Beban arus pada 2 lampu 500W dan 1 setrika 350W: $1050 / 220=6,1$ Ampere, terjadi trip setelah 8 detik.
- Beban arus 3 lampu 500W: 2,27 x $3=6,8$ Ampere, terjadi trip setelah 4 detik.

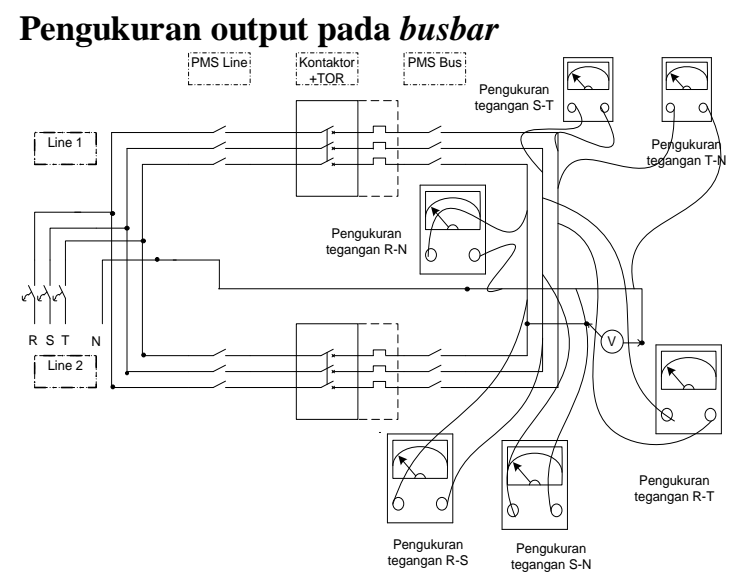

Gambar 12. Titik Pengukuran output pada busbar

Tabel 4. Hasil Pengukuran output pada busbar

\begin{tabular}{ccccccc}
\hline Besaran & \multicolumn{6}{c}{ Line 2 close } \\
\cline { 2 - 7 } & R-N & S-N & T-N & R-S & S-T & T-R \\
\hline $\begin{array}{c}\text { Tegangan } \\
\text { (V) }\end{array}$ & 220 & 220 & 220 & 400 & 380 & 390 \\
\hline
\end{tabular}

\section{Analisa Program}

Didalam analisis program ini akan dijelaskan mengenai maksud dari intruksi-intruksi program aplikasi PLC. Analisa program meliputi intruksi dari ladder diagram dan penjelasan melalui kode mnemonic.

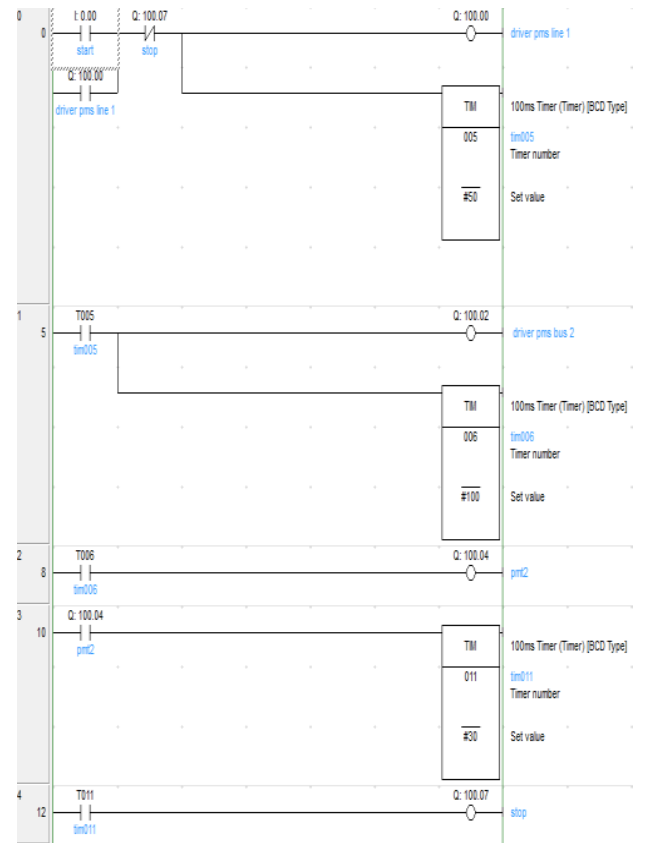

Gambar 13. Potongan program aplikasi PLC untuk OVERLOAD dan mode stand by 
Tabel 3.5. Analisa kode mnemonic

\begin{tabular}{|c|c|c|c|}
\hline Alamat & $\begin{array}{c}\text { Kode } \\
\text { Operasi }\end{array}$ & Data & Keterangan \\
\hline \multicolumn{4}{|c|}{ RUNG 0} \\
\hline 00000 & LD & 00000 & $\begin{array}{l}\text { Saklar 00 akan } \\
\text { menghidupkan } \\
\text { rangkaian sehingga } \\
\text { program bekerja } \\
\text { (START) }\end{array}$ \\
\hline 00001 & OR & 10001 & $\begin{array}{c}\text { Intruksi berfungsi } \\
\text { untuk menahan } \\
\text { status ON alamat } \\
10001 \text { (PMS Line } \\
\text { 2) }\end{array}$ \\
\hline 00002 & $\begin{array}{l}\text { AND } \\
\text { NOT }\end{array}$ & 10007 & $\begin{array}{l}\text { Berfungsi sebagai } \\
\text { saklar OFF }\end{array}$ \\
\hline 00003 & OUT & 10001 & $\begin{array}{l}\text { Merupakan alamat } \\
\text { output yang } \\
\text { terhubung pada } \\
\text { PMS Line } 2\end{array}$ \\
\hline 00004 & TIM & $\begin{array}{l}005 \\
\# 50\end{array}$ & $\begin{array}{c}\text { Merupakan alamat } \\
\text { timer selama } 5 \\
\text { detik }\end{array}$ \\
\hline \multicolumn{4}{|c|}{ RUNG 1} \\
\hline 00005 & LD & T005 & $\begin{array}{c}\text { Intruksi ini bekerja } \\
\text { apabila alamat TIM } \\
005 \text { telah terpicu }\end{array}$ \\
\hline 00006 & AND & 10002 & $\begin{array}{l}\text { Merupakan alamat } \\
\text { output yang } \\
\text { terhubung pada } \\
\text { PMS Bus } 2\end{array}$ \\
\hline 00007 & TIM & $\begin{array}{c}006 \\
\# 100\end{array}$ & $\begin{array}{c}\text { Merupakan alamat } \\
\text { timer selama } 10 \\
\text { detik }\end{array}$ \\
\hline \multicolumn{4}{|c|}{ RUNG 2} \\
\hline 00008 & LD & T006 & $\begin{array}{c}\text { Intruksi ini bekerja } \\
\text { apabila alamat TIM } \\
006 \text { telah terpicu }\end{array}$ \\
\hline 00009 & OUT & 10004 & $\begin{array}{c}\text { Merupakan alamat } \\
\text { output yang } \\
\text { terhubung pada } \\
\text { Kontaktor } 2 \\
\end{array}$ \\
\hline \multicolumn{4}{|c|}{ RUNG 3} \\
\hline 00010 & LD & 10004 & $\begin{array}{l}\text { Intruksi ini bekerja } \\
\text { apabila alamat } \\
10004 \text { (Kontaktor } \\
\text { 2) telah terpicu }\end{array}$ \\
\hline 00011 & TIM & $\begin{array}{l}011 \\
\# 30\end{array}$ & $\begin{array}{c}\text { Merupakan alamat } \\
\text { timer selama } 10 \\
\text { detik }\end{array}$ \\
\hline \multicolumn{4}{|c|}{ RUNG 4} \\
\hline 00012 & LD & T011 & $\begin{array}{l}\text { Intruksi ini bekerja } \\
\text { apabila alamat } \\
10004 \text { (PMS Line } \\
\text { 2) telah terpicu }\end{array}$ \\
\hline 00013 & OUT & 10007 & $\begin{array}{c}\text { Program berhenti } \\
\text { (STOP) }\end{array}$ \\
\hline
\end{tabular}

\section{KESIMPULAN}

Dari uraian di atas, dapat kita ambil kesimpulan sebagai berikut :

- Thermal Overload Relay pada alat ini bekerja pada rentang beban arus antara 5,2 A $-8 \mathrm{~A}$.

- Mekanisme kerja simulasi overload pada alat, kontaktor akan trip setelah Thermal Overload Relay mendeteksi beban lebih kemudian mengirimkan sinyal pada PLC yang kemudian akan memerintahkan kontaktor untuk trip.

- Pada uji coba simulasi overload (alat diberi beban), Thermal Overload Relay di setting pada batas arus 6 A. Pada salah satu percobaan variasi beban yaitu, 2 buah lampu Osram HWL (MBFT) E-40 $500 \mathrm{~W}$ dan setrika Philips HI-114 $350 \mathrm{~W}$ dengan total beban sebesar 6,1 A akan trip dalam 8 detik.

\section{DAFTAR PUSTAKA}

1. Bishop, Owen. 2004. Dasar-Dasar Elektronika. Jakarta: Erlangga.

2. Eko Putra, Agfianto. 2004. PLC : Konsep, Pemprograman dan Aplikasi (Omron CPM1A/CPM2A dan ZEN Programmable Relay). Yogyakarta: GAVAMEDIA.

3. Hasan, Esan. 2000. Rangkaian Dasar Elektronika. Bandung Ganesa: Exact.

4. Malvino, Albert Paul. 1994. Prinsip-Prinsip Elektronika. Jakarta: Erlangga.

5. Mukti Hermawan, Tri. 2009. Aplikasi PLC SYSMAC OMRON CPM1A 30I/O dengan Sensor Limit Switch RX KW12 pada Pintu Gerbang Otomatis sebagai Bagian Sistem Otomatisasi Rumah, Semarang : Universitas Diponegoro.

6. Panca manunggal. Buku Panduan Training PLC OMRON Tingkat Dasar. Jakarta : Panca manunggal.

7. Setiawan, Hendrix. 2007. Aplikasi dan Pemprograman Programmable Logic Controller (PLC) dalam Proses Pengaturan Sistem Kerja Mesin Penggiling Biji Kopi Otomatis, Semarang : Universitas Diponegoro.

8. Suwanto. 2005. Aplikasi PLC sebagai Penentuan Kecepatan Putar Motor DC dengan Indikator Lampu $220 \mathrm{~V}$ AC Menggunakan Programming Console, Semarang :Universitas Diponegoro.

9. Zuhal dan Zhanggischan. 2004. Prinsip Dasar Elektroteknik. Jakarta: PT Gramedia Pustaka Utama. 